\title{
Aortic valve and aortic arch pathology after coarctation repair
}

\author{
J W Roos-Hesselink, B E Schölzel, R J Heijdra, S E C Spitaels, F J Meijboom, E Boersma, \\ A J J C Bogers, M L Simoons
}

Heart 2003;89:1074-1077

See end of article for authors' affiliations

\section{Correspondence to:} Dr J W Roos-Hesselink Thoraxcentre, Ba308, Erasmus MC Rotterdam Dr Molewaterplein 40, 3015 GD Rotterdam, Netherlands;

j.roos@erasmusmc.nl

Accepted 25 March 2003

\begin{abstract}
Objective: To investigate the incidence of clinical problems related to a bicuspid valve (aortic stenosis and regurgitation) and the incidence of ascending aorta and aortic arch pathology in combination with coarctation repair.

Patients: 124 adult patients after surgical correction of aortic coarctation were studied. The incidence of aortic valve, ascending aorta, and aortic arch pathology was determined using echocardiography and magnetic resonance imaging. The median age at coarctation repair was 9 years and at last follow up 28 years.

Results: Three patients died from aorta pathology. Aortic valve disease was found in $63 \%$ of the patients, requiring an intervention in $22 \%$, at a median of 13 years after coarctation repair. Ascending aorta dilatation was observed in $28 \%$ and aortic arch abnormalities in $23 \%$, among whom kinking of the aortic arch was found in $12 \%$. Antihypertensive medication was used in $24 \%$. In the patients with hypertension the age at operation and age at follow up were significantly higher $(p=0.0001$ and $\mathrm{p}<0.0001$, respectively).

Conclusion: In addition to the well known problems of hypertension and recoarctation, aortic valve and aortic arch pathology are commonly encountered in patients with previous coarctation repair. Aortic abnormalities may predispose to dilatation and dissection, thus necessitating careful lifelong attention in all patients with coarctation.
\end{abstract}

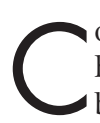
oarctation of the aorta accounts for $8 \%$ of congenital heart disease. In the past, coarctation was considered to be a simple "correctable lesion" and surgery, first performed in 1944, was believed to be curative. In keeping with this belief, normotensive patients were often discharged postoperatively without long term follow up. However, as increasing numbers of patients with surgically corrected coarctation reached maturity, it has become clear that almost a third of patients become or remain hypertensive, despite correction of their lesion, with an increased risk of accelerated atherosclerosis and end organ damage. ${ }^{1}$ Furthermore, recoarctation occurs in $3-35 \% .^{2-4}$

The association of a bicuspid aortic valve with coarctation of the aorta is well recognised, but estimates of bicuspid valve in patients with coarctation range from $25-85 \% .^{25}$ The clinical significance of a bicuspid valve in patients with coarctation is not well established.

To address these issues, we retrospectively studied patients after coarctation repair seen in our department for adult congenital heart disease with emphasis on both aortic valve and aortic arch pathology.

The specific purpose of this study was, firstly, to assess the prevalence of aortic stenosis or regurgitation in these patients; secondly, to assess how often dilatation of the ascending aorta and pathology of the aortic arch occur in patients with coarctation; and thirdly, to assess a possible correlation of aortic arch pathology with hypertension or recoarctation.

\section{METHODS}

All patients seen in our department for adult congenital heart disease with surgically corrected coarctation were reviewed. They were included in the study if at least two follow up echocardiographic studies were available, containing two dimensional imaging of the aortic root in long axis parasternal views and complete Doppler evaluation of the aortic valve.
Echocardiograms were performed with the use of standard commercially available equipment. Magnetic resonance imaging (MRI) of the thoracic aorta was performed.

Aortic valve morphology was examined by echocardiography in the two dimensional parasternal long axis and short axis views. The presence in short axis views of only two cusps in systole, diastole, or both identified a bicuspid aortic valve. The presence or absence of aortic regurgitation or stenosis was determined with the use of Doppler and colour Doppler echocardiography. The degree of aortic regurgitation was graded as minor, moderate, or severe. We report aortic stenosis as present if the peak velocity over the aortic valve with continuous wave Doppler velocity was $>2 \mathrm{~m} / \mathrm{s}$.

The diameter of the ascending aorta was measured with echocardiography and MRI perpendicular to the long axis of the aorta with use of the leading edge technique at the level of the sinuses of Valsalva. Dilatation was defined as a diameter of $40 \mathrm{~mm}$ or more.

Aortic arch morphology was examined with echocardiography and MRI. Abnormalities were categorised as arch hypoplasia, cervical aortic arch, or kinking of the aortic arch.

The diagnosis of recoarctation was limited to patients who underwent a reintervention for recoarctation.

Hypertension was considered to be present if medication for hypertension was prescribed.

Data were analysed by means of the Wilcoxon test or Fisher's exact test as appropriate. Age and duration of follow up are given as median values with the corresponding 25 th and 75 th centiles or with ranges.

A probability value of $\mathrm{p}<0.05$ was considered significant.

\section{RESULTS}

Of the 149 adult patients who had undergone surgery for coarctation and follow up at our department, 25 had inadequate echocardiograms. The baseline characteristics did 


\begin{tabular}{|lc|}
\hline \multicolumn{3}{|l|}{ Table 1 Associated heart defects in } \\
124 patients with aortic coarctation \\
\hline Associated defects & Number \\
\hline Ventricular septal defect & $18(15 \%)$ \\
Persistent ductus arteriosus & $16(13 \%)$ \\
Atrial septal defect & $4(3 \%)$ \\
Abnormal mitral valve & $4(3 \%)$ \\
Transposition of the great arteries & $3(2 \%)$ \\
Dextrocardia & $1(1 \%)$ \\
\hline
\end{tabular}

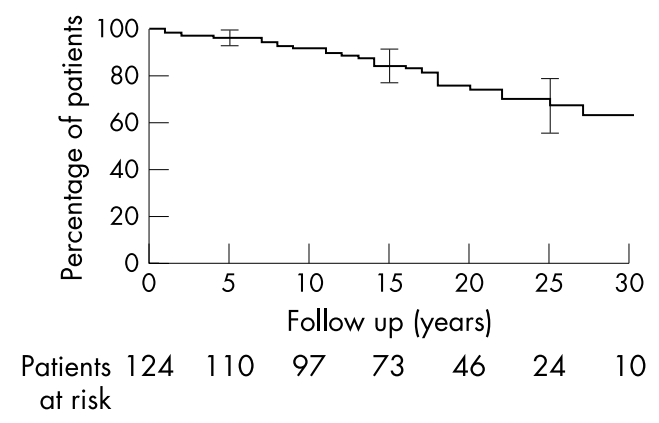

Figure 1 Survival free of aortic valve disease.

not differ between those patients with and those without adequate echocardiograms. One hundred twenty four patients (71 men and 53 women) had adequate echocardiograms and are included in this report. They had been operated on by several techniques: resection and end to end anastomosis (91), subclavian flap (14), and graft plasty (10). In nine patients the surgical technique was not described in detail. Associated intracardiac anomalies were recorded at the time of surgery in 46 patients $(37 \%)$ (table 1 ). The median age at coarctation repair was 9 years (range $4-16$ years). The time from surgery to the last follow up was 18 years (range 13-25 years). The median age at last follow up was 28 years (range $20-36$ years). During follow up in the department for adult congenital heart disease three cardiac deaths occurred: one due to acute ascending aorta dissection 14 years after coarctation repair and one during aortic arch surgery 20 years after coarctation repair; the third patient died of aortic valve endocarditis with massive acute aortic regurgitation 18 years after coarctation repair.

\section{Aortic valve disease}

Forty eight patients had a bicuspid aortic valve, 30 patients had a trileaflet valve, and in 46 patients it was difficult to differentiate between a bicuspid and a trileaflet valve; thus, a bicuspid valve was found in $62 \%$ (48 of 78 patients). During follow up, aortic valve intervention was performed in 27 patients (22\%): 16 for aortic stenosis, eight for regurgitation, and three for combined stenosis and regurgitation. Surgery

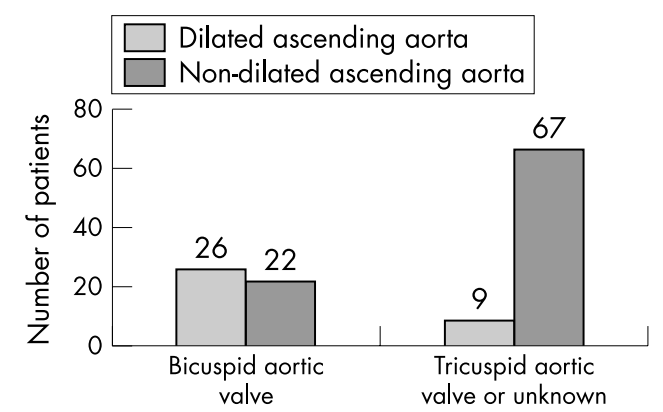

Figure 2 Dilatation of the ascending aorta in relation to aortic valve morphology.

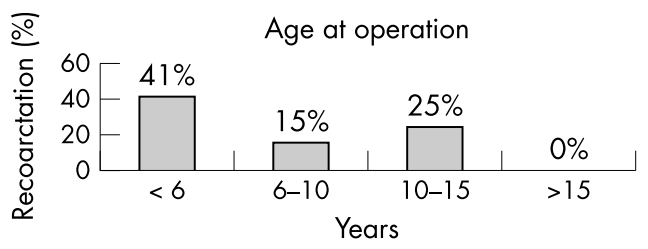

Figure 3 Age at operation in relation to recoarctation.

was performed in 25 patients and two underwent balloon dilatation of a stenotic aortic valve. Figure 1 shows survival free of aortic valve intervention after coarctation repair. In the 97 patients without aortic valve intervention, 23 patients had aortic stenosis and 28 had aortic regurgitation (mild in 18, moderate in 5 , and severe in 5 patients). In total, aortic valve disease was observed in $63 \%$ of our patients. Of the patients with a bicuspid valve this percentage was as high as $70 \%$. Several factors have been suggested to be related to the development of aortic regurgitation, particularly hypertension, recoarctation, dilatation of the ascending aorta, and aortic arch pathology. ${ }^{67}$ However, none of these factors was significantly correlated with aortic regurgitation in our series.

\section{Aortic pathology}

In 60 patients (48\%) we found aortic pathology. Dilatation of the ascending aorta was found in 35 patients $(28 \%)$. This was particularly prominent in patients with a bicuspid valve (fig 2). In 28 patients aortic arch pathology was established (23\%). Of these, hypoplasia of the arch was found in 10 patients, a cervical aortic arch in 4 , severe kinking of the aorta in 8 , and both kinking and a cervical arch in 8; 2 patients had hypoplasia and a cervical arch.

\section{Recoarctation}

In 28 patients $(23 \%)$ recoarctation occurred and was treated with surgery in 10 and with balloon dilatation in 18 patients a median of 16 years after the initial repair. Figure 3 shows the age at first repair in relation to the need for a second intervention. Patients operated on at younger age more often needed a reintervention for coarctation.

To assess the effect of recoarctation repair on the severity of aortic regurgitation we reviewed the six patients with

Table 2 Differences between patients with and without hypertension

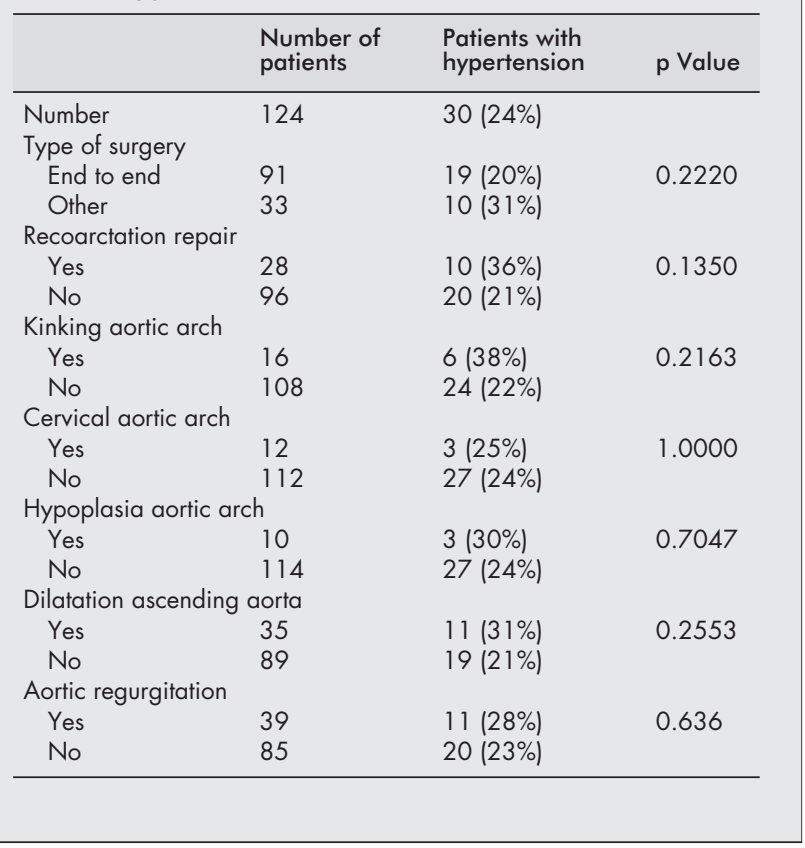


moderate to severe aortic regurgitation who underwent an intervention for recoarctation. Regurgitation remained unchanged in four patients, increased in one, and decreased in one patient.

\section{Hypertension}

Of the 124 patients, 30 (24\%) were taking medication for hypertension at the time of the last outpatient visit. Table 2 shows characteristics of patients with and without hypertension. In the patients with hypertension the age at operation was significantly higher than in patients without hypertension ( $13 \vee 6$ years; $\mathrm{p}=0.0001$ ). Also, the age at follow up was higher in the patients with hypertension (38 v 24 years; $\mathrm{p}<0.0001)$.

\section{DISCUSSION}

In this series of patients after coarctation repair, disease of the aortic valve or aortic arch was observed frequently.

Aortic valve disease was found in $63 \%$ of the patients 19 years after coarctation repair, of whom a third needed aortic valve intervention at a median of 13 years after coarctation repair. Thus, aortic valve problems are a frequent cause of morbidity and mortality of coarctation patients. The association of aortic valve disease and coarctation is mentioned in several reports. ${ }^{58}$ However, the incidence of aortic valve problems after coarctation repair found in our study is surprisingly high, necessitating careful lifelong follow up of all patients with coarctation.

A bicuspid aortic valve was found in $62 \%$ of our coarctation patients, which is in line with other reports. ${ }^{25}$ However, the incidence of aortic valve pathology is higher than in studies of bicuspid aortic valves without coarctation, which emphasises the additional role of the coarctation in the development of aortic valve problems. ${ }^{9-12}$ It is likely that hypertension is a cause of the increased incidence of aortic valve problems. Furthermore, the remaining gradient over the coarctation region causes more stress on the aortic valve and aortic wall, resulting in aortic valve disease.

Nevertheless, we did not find any influence of repairing the recoarctation on the degree of aortic regurgitation.

Dilatation of the ascending aorta was found in $28 \%$ of the patients. One study has shown a high incidence of ascending aorta dissection in patients with coarctation and bicuspid aortic valve, probably caused by dilatation of the ascending aorta in combination with persistent hypertension. Others suggest that disease of the aortic valve and the aorta itself reflects an intrinsic abnormality of the media, possibly cystic medial necrosis. ${ }^{6}{ }^{10} 13-15$ We did not find a significant correlation between dilatation of the ascending aorta and hypertension. However, we lost one patient because of dissection, who indeed had a bicuspid aortic valve and a dilated ascending aorta in combination with hypertension. Further study is necessary to determine what features or combinations of features are the most important risk factors for aortic dissection in these patients. Whether prophylactic surgery of the dilated ascending aorta is indicated in these patients cannot be concluded from our data but a more aggressive approach seems appropriate, especially if we take into account other reports of ascending aorta dissection and substantial late mortality in patients with coarctation. ${ }^{10} 1216$

Aortic arch pathology, other than ascending aorta dilatation, was present in $23 \%$ of our patients. Not only arch hypoplasia, but also a cervical aortic arch and a striking number of patients with kinking of the aortic arch were found. These abnormalities of the arch may have an additional role in the development of hypertension and valve disease in these patients. Patients with kinking of the aortic arch more often were hypertensive than patients without kinking (38\% v 22\%), although, because of the small numbers, we could not prove that the difference was significant $(p=0.22)$. Kinking of the aortic arch has not been reported frequently, possibly because identification of this pathology was difficult before the era of high quality echocardiography and magnetic resonance imaging. In nearly half of the patients we found some form of pathology of the ascending aorta or aortic arch, apart from the coarctation, suggesting that this is a disease of all parts of the thoracic aorta.

\section{Hypertension}

In our study $24 \%$ of the patients were taking medication for hypertension, comparable with other studies. ${ }^{17-19}$ We confirmed the clear relation of hypertension with age at operation and age at follow up, but did not found a correlation between hypertension and the incidence of aortic regurgitation..$^{20}$

\section{Study limitations}

The incidence of aortic valve and aortic arch pathology may be slightly overestimated as a result of patient selection because a complete cohort of patients who had undergone surgery was not described. However, we followed up the majority of patients after their operation in our centre. In comparison with other coarctation cohorts, our patients had fewer associated heart defects, which is compatible with less selection of more complex coarctation patients. ${ }^{22}$ It is more appropriate to assume that the high quality of diagnostic tools give better insight into the real incidence of this pathology.

\section{Conclusion}

In addition to the well known problems of hypertension and recoarctation, aortic valve and aortic arch pathology are commonly encountered in patients with previous coarctation repair. Aortic abnormalities may predispose to dilatation and dissection, thus necessitating careful lifelong attention in all coarctation patients.

\section{Authors' affiliations}

J W Roos-Hesselink, B E Schölzel, R J Heijdra, S E C Spitaels, F J Meijboom, E Boersma, M L Simoons, Department of Cardiology, Thoraxcentre, Erasmus MC, Rotterdam, Netherlands A J J C Bogers, Department of Cardiothoracic Surgery, Thoraxcentre

\section{REFERENCES}

1 Cohen M, Fuster V, Steele PM, et al. Coarctation of the aorta: long-term follow-up and prediction of outcome after surgical correction. Circulation 1989;80:840-5

2 Presbitero $\mathbf{P}$, Demarie D, Villani $M$, et al. Long term results (15 to 30 years) of surgical repair of aortic coarctation. Br Heart $J$ 1987;69:65-70.

3 Brouwer $\mathbf{M H}$, Kuntze EE, Ebels T, et al. Repair of aortic coarctation in infants. J Thorac Cardiovasc Surg 1991;101:1093-8.

4 Dietl CA, Torres AR, Favaloro RG, et al. Risk of recoarctation in neonates and infants after repair with patch aortoplasty, subclavian flap, and the combined resection-flap procedure. J Thorac Cardiovasc Surg 1992;103:724-32

5 Stewart AB, Ahmed R, Travill CM, et al. Coarctation of the aorta, life and health $20-44$ years after surgical repair. Br Heart J 1993;69:65-70.

6 Hahn RT, Roman M, Mogtader AH, et al. Association of aortic dilation with regurgitant, stenotic and functionally notmal bicuspid aortic valves. J Am Coll Cardiol 1992;19:283-8.

7 Mulay AV, Ashraf S, Watterson KG. Two-stage repair of adult coarctation of the aorta with congenital valvular lesions. Ann Thorac Surg 1997:64:1309-11.

8 Westaby S, Parnell B, Pridie RB. Coarctation of the aorta in adults. J Cardiovasc Surg 1987;28:124-7.

9 Lindsay J. Coarctation of the aorta, bicuspid aortic valve and abnormal ascending aortic wall. Am J Cardiol 1988;61:182-3.

10 Ward C. Clinical significance of the bicuspid aortic valve. Heart 2000;83:81-5.

11 Nistri S, Sorbo MD, Marin M, et al. Aortic root dilatation in young men with normally functioning bicuspid aortic valves. Heart 1999;82:19-22.

12 Folger GM Jr, Stein PD. Bicuspid aortic valve morphology when associated with coarctation of the aorta. Cathet Cardiovasc Diagn 1984; 10:17-25.

13 McKusick VA. Association of congenital bicuspid aortic valve and Erdheim's cystic medial necrosis. Lancet 1972;i:1026-7.

14 Bonderman D, Gharehbaghi-Scgnell E, Wollenek G, et al. Mechanisms underlying aortic dilatation in congenital aortic valve malformation. Circulation 1999;99:2138-43. 
15 Niwa K, Perloff JK, Bhuta SM, et al. Structural abnormalities of great arterial walls in congenital heart disease: light and electron microscopic analyses. Circulation 2001;103:393-400.

16 Gott VL, Greene PS, Alejo DE, et al. Replacement of the aortic root on patients with Marfan's syndrome. N Engl J Med 1999;340:1307-13.

17 Clarkson PM, Nicholson MR, Barratt-Boyes BG, et al. Results after repair of coarctation of the aorta beyond infancy: a 10 to 28 year follow-up with particular reference to late systemic hypertension. Am J Cardiol 1983;51:1481-9.

18 Kappetein PA, Guit GL, Bogers AJJC, et al. Noninvasive long-term follow-up after coarctation repair. Ann Thorac Surg 1993;55:1153-9.
19 Swan L, Wilson N, Houston AB, et al. The long-term management of the patient with an aortic coarctation repair. Eur Heart J 1998; 19:382-6.

20 Seirafi PA, Warner KG, Geggel RL, et al. Repair of coarctation of the aorta during infancy minimizes the risk of late hypertension. Ann Thorac Surg 1998:66:1378-82.

21 Koller M, Rothlin M, Senning A. Coarctation of the aorta: a review of 362 operated patients. Long-term follow-up and assessment of prognostic variables. Eur Heart J 1987;8:670-9.

22 Becker AE, Becker M, Edwards JE. Anomalies associated with coarctation of aorta. Particular reference to infancy. Circulation 1970;41:1067-75

\section{IMAGES IN CARDIOLOGY}

\section{Myocardial infarction with myocardial rupture}

A

76 year old man was brought in after a syncope. His past medical history included radiotherapy for lung cancer. Upon arrival, he was pale, diaphoretic, and complained of shortness of breath. He quickly became haemodynamically unstable. The initial ECG showed inferior ST segment elevation while a transthoracic echocardiogram revealed a pericardial effusion.

After stabilising his condition, transoesophageal echocardiography documented a circumferential pericardial effusion and an associated hypokinetic inferior wall. Further evaluation allowed visualisation of a myocardial rupture near the apex (panel A) while Doppler colour flow imaging exposed flow from two sites with each systole (panels B and C).

The patient underwent emergency heart surgery and a $1.2 \mathrm{~cm}$ rupture caused by myocardial infarction was found near the apical posterior wall. The patient had an unremarkable postoperative period and was well upon follow up one month later.

Q H Ly

R Lebeau

h.ly@sympatico.ca
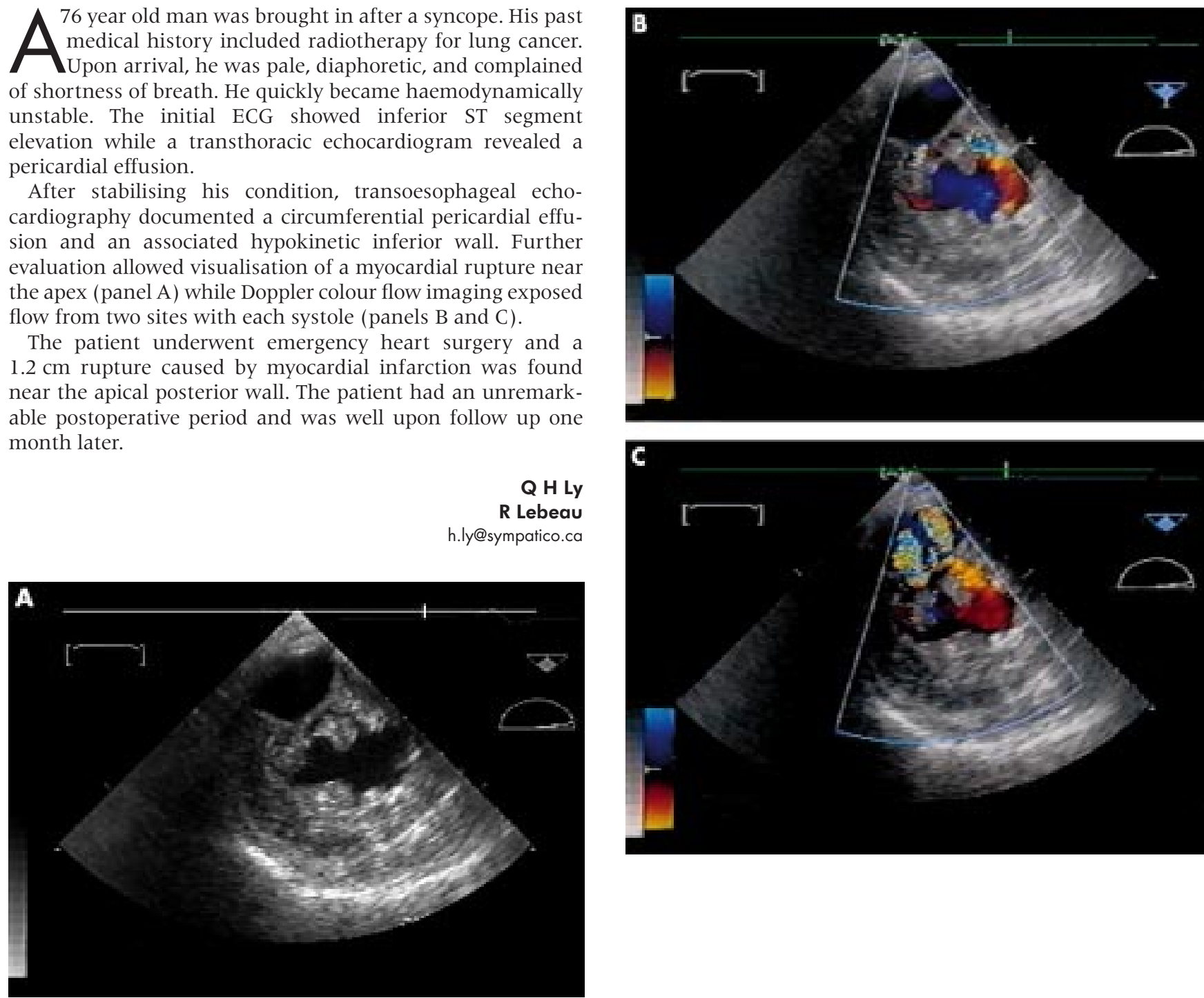